\title{
Spontaneous Uterine Rupture in the First Trimester : A Case Report
}

\begin{abstract}
Uterine rupture is one of the most feared obstetric complications affecting the pregnant woman and fetus. Most of the cases have various risk factors and mainly occur during the second or third trimester. However, spontaneous uterine rupture during the first trimester is extremely rare. We experienced a case of spontaneous uterine rupture in a 36-yr-old multiparous woman without definite risk factors. The initial impression was a hemoperitoneum of an unknown origin with normal early pregnancy. Intensive surgical method would be needed for accurate diagnosis and immediate management in bad situation by hemoperitoneum even though a patient was early pregnancy.
\end{abstract}

Key Words : Uterine Rupture; Hemoperitoneum; Pregnancy Trimester, First
Young-Joon Park, Ki-Young Ryu, Jong-In Lee ${ }^{\star}$, Moon-II Park

Department of Obstetrics and Gynecology, Department of Surgery ${ }^{*}$, Kwandong University College of Medicine, Myongji Hospital, Koyang; Department of Obstetrics and Gynecology, Hanyang University ${ }^{\dagger}$ College of Medicine, Seoul, Korea

Received : 10 September 2004 Accepted : 6 November 2004

Address for correspondence

Young-Joon Park, M.D.

Department of Obstetrics and Gynecology,

Kwandong University College of Medicine, Myongji

Hospital, $697-24$ Hwajung-dong, Dukyang-gu, Koyang

412-270, Korea

Tel : +82.31-810-6390, Fax : +82.31-969-0500

E-mail : pyjoon@kwandong.ac.kr

\section{INTRODUCTION}

Uterine rupture is one of the most dangerous obstetric situations, carrying an increased risk of maternal and perinatal morbidity and mortality $(1,2)$. Uterine rupture during gestation is mainly found during the second or third trimester in the women whose past history includes Cesarean delivery $(1,3)$. Spontaneous uterine rupture of unknown cause during the early pregnancy is extremely rare. Few researchers have reported spontaneous uterine rupture without underlying causes during the first trimester. We report a case in which a multiparous woman showed hemoperitoneum by spontaneous uterine rupture in early pregnancy.

\section{CASE REPORT}

A 36-yr-old multiparous (2-0-0-2) woman was admitted to our emergency room, complaining of suddenly developed acute abdominal pain. At the time of presentation, she was 10 weeks pregnant by dates and urine hCG. Her menstrual history was relatively regular, and past obstetric history consisted of two spontaneous vaginal deliveries at term. Meanwhile, the patient underwent appendectomy in the past history. The patient had intermittent vaginal spotting for two weeks before the presentation but did not visit a hospital. On the physical examination, her vital sign was stable, and right lower quadrant tenderness and rebound tenderness were severe.

On the transvaginal ultrasonogram, the 6 week-sized intrauterine gestational sac with mild compression was noted (Fig. 1). In the gestational sac, neither fetal part nor heart beat was found, but two yolk sacs were observed. Subchorionic hematoma was not shown. Both ovaries were hard to be detected. A large amount of blood clot was observed around the uterus. Abdominopelvic computerized tomography revealed a large amount of blood clot around the uterus and cul-de-sac (Fig. 2). Also a large quantity of blood-like fluid was noted in the perihepatic, perisplenic, and paracolic space. However, no lesion that was considered to induce such hemorrhage was found.

In this context, emergency operation was determined to conduct under the hemoperitoneum impression on 6 weeks gestation. Laparotomy was performed and revealed a large amount of blood clots in the pelvic and abdominal cavity. After removing the blood clots, small uterine rupture $(3 \mathrm{~mm})$ was observed on the upper portion of the left fundus (Fig. 3). A probe was inserted into the rupture to identify that it was open to the uterine cavity. A suction catheter was inserted through the rupture site to perform suction of gestational material in the uterine cavity, and the edges of the rupture was repaired with one layer suture. Because the patient wanted no more pregnancy, bilateral tubal ligation was performed. The remained 


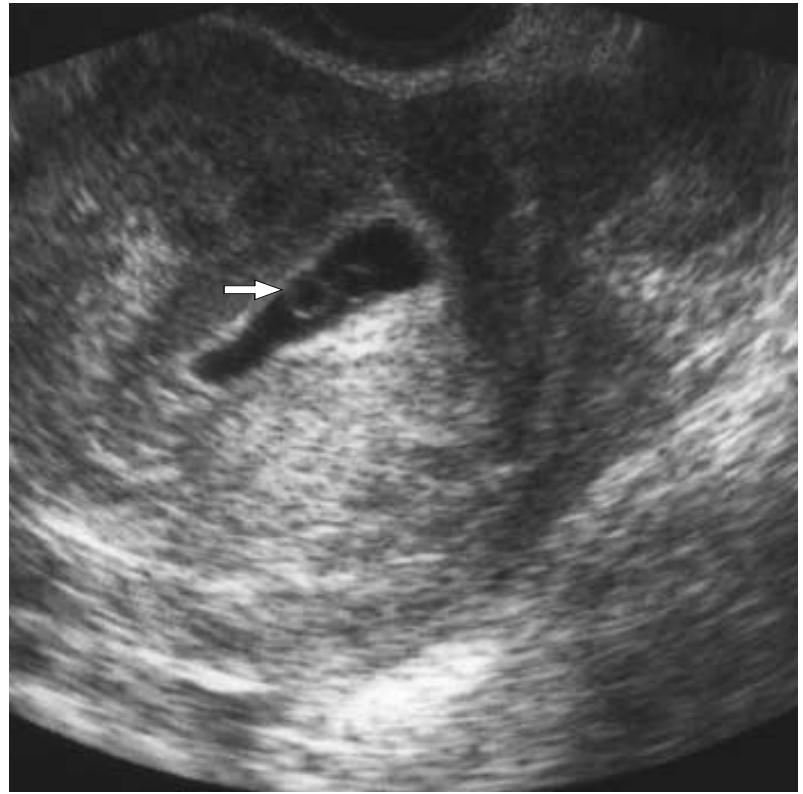

Fig. 1. On the vaginal ultrasonogram, a compressed gestational sac is found within the uterus. Two yolk sacs (arrow) are observed within the sac, but fetal part is not shown.

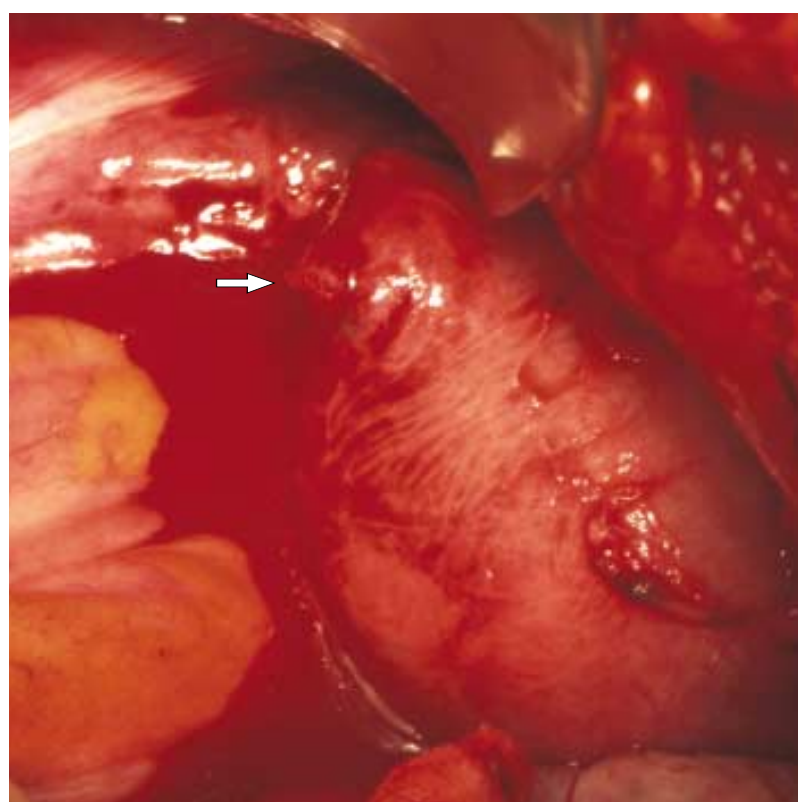

Fig. 3. On the photography after laparotomy, small sized uterine rupture (arrow) was observed on the fundus.

blood in the abdominal cavity was removed and then the abdominal wall was closed.

\section{DISCUSSION}

According to the several information about uterine rupture

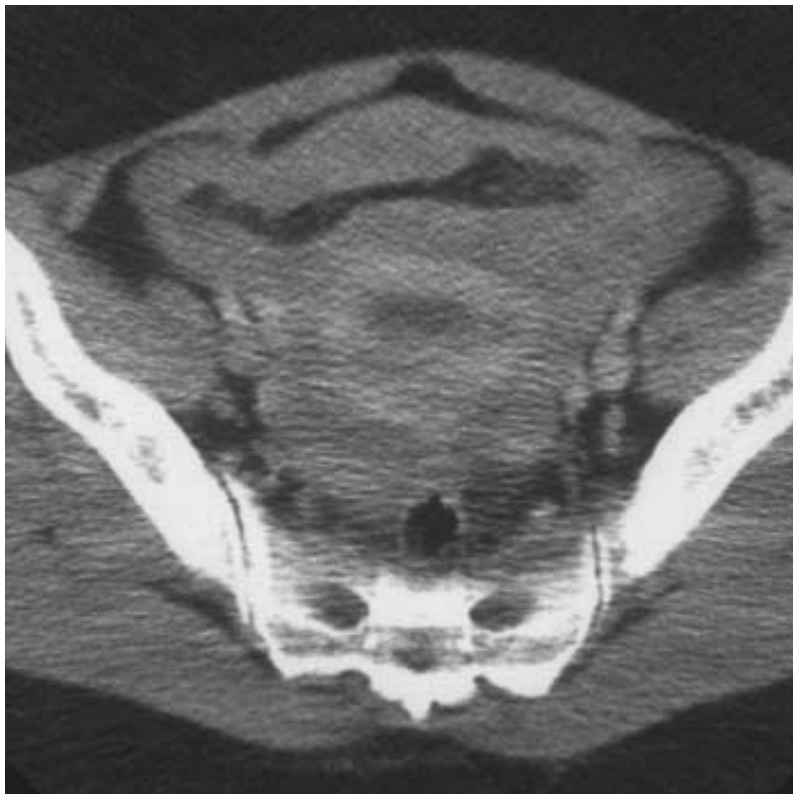

Fig. 2. On the abdominal CT, high attenuation fluid collection, suggesting blood clots, is found around the uterus but no other abnormal findings are observed.

obtained from the literature, most of the cases had various risk factors (4). It is evident that the single most important factor in determining the risk of uterine rupture is whether the uterus has a previous scar or not (1). The past injuries such as Cesarean delivery, hysteroscopic resection of uterine septum, myomectomy, and cornual resection are considered to be the causes of uterine rupture (5). It is reported that spontaneous rupture of unscarred uterus occurs in 1 in 15,000 (6). It may occur in a patient who has high parity (7), placenta increta or percreta, adenomyosis, abortion with instrumentation, manipulation during delivery, induced delivery by misoprostol (8), vigorous fundal pressure during delivery, cocaine abuse (9) and idiopathic cause (6). Most of the above listed causes shows that uterine rupture is mainly occur before or during labor after the second trimester. Also some researchers reported on the uterine rupture observed in women who were not pregnant $(10,11)$.

However, spontaneous uterine rupture during the first trimester like our case, is extremely rare. Only a few cases were found in the literature. In the case reported by Biljan et al. (12), uncomplicated evacuation of the uterus for suspected retained products of pregnancy was performed following second delivery. And the previous abortion cannot be considered to induce uterine rupture because the patient had normal spontaneous vaginal delivery at term for the third trimester. In our case report, however, the patient did not have the history about of the curettage of the uterus. So the cause of the rupture was not clear.

Uterine rupture is usually a serious and potentially catastrophic event because of massive uterine bleeding. Early surgical intervention is the key to successful treatment of uter- 
ine rupture (4). In this situation, hemoperitoneum can be regarded as non-obstetric cause or immediate management can be delayed, because spontaneous uterine rupture in early pregnancy having gestational sac is very uncommon (13). Conclusively, intensive surgical method would be needed for accurate diagnosis and immediate treatment when a patient was in bad situation by hemoperitoneum in early pregnancy.

\section{REFERENCES}

1. Turner MJ. Uterine rupture. Best Pract Res Clin Obstet Gynaecol 2002; 16: 69-79.

2. Kieser KE, Baskett TF. 10-year population-based study of uterine rupture. Obstet Gynecol 2002; 100: 749-53.

3. Kong KY, Chang SK, Kim YJ, Lee JY, Chung JK. A clinical evaluation on the rupture of the gravid uterus. Korean J Obstet Gynecol 1993; 36: 1486-90.

4. Suner S, Jagminas L, Peipert JF, Linakis J. Fatal spontaneous rupture of a gravid uterus: Case report and literature review of uterine rupture. J Emerg Med 1996; 14: 181-5.

5. Cunningham FC, Gant NF, Leveno KJ, Gilstrap III LC, Hauth JC, Wenstrom KD. Obstetrical hemorrhage In: Williams Obstetrics,
Cunningham FC, Gant NF, Leveno KJ, Gilstrap III LC, Hauth JC, Wenstrom KD. 21st ed. McGraw-Hill, 2001; 619-69.

6. Sallam AH, Preston J. Idiopathic uterine perforation in late pregnancy. J Obstet Gynaecol 2002; 22: 317.

7. Miller DA, Goodwin TM, Gherman RB, Paul RH. Intrapartum rupture of the unscarred uterus. Obstet Gynecol 1997; 89: 671-3.

8. Berghahn L, Christensen D, Droste S. Uterine rupture during secondtrimester abortion associated with misoprostol. Obstet Gynecol 2001; 98: 976-7.

9. Mishra A, Landzberg BR, Parente JT. Uterine rupture in association with alkaloidal cocaine abuse. Am J Obstet Gynecol 1995; 173: 243-4.

10. Chan LY, Yu VS, Ho LC, Lok YH, Hui SK. Spontaneous uterine perforation of pyometra: a report of three cases. J Reprod Med 2000; 45 : 857-60.

11. Ding DC, Chu TY, Liu JY. Menstruation-induced uterine rupture. Int J Obstet Gynaecol 2000; 69: 171-2.

12. Biljan MM, Cushing K, McDicken IW, Garden AS. Spontaneous uterine rupture in the first trimester of pregnancy. J Obstet Gynecol 1996; 16: 174-5.

13. Choi KD, Choi HK, Lee HS, Kim CB, Lee GN. A case of spontaneous rupture of the uterus with placenta increta in early pregnancy. Korean J Obstet Gynecol 1996; 39: 1359-64. 